Check for updates

Cite this: RSC Chem. Biol., 2020, 1,148

Received 15th April 2020, Accepted 15th June 2020

DOI: 10.1039/d0cb00045k

rsc.li/rsc-chembio

\title{
Glycosylated cyclophellitol-derived activity-based probes and inhibitors for cellulases $\dagger$
}

\author{
Casper de Boer, (D) $\ddagger^{\mathrm{a}}$ Nicholas G. S. McGregor, $\ddagger^{\mathrm{b}}$ Evert Peterse, ${ }^{a}$ \\ Sybrin P. Schröder, ${ }^{a}$ Bogdan I. Florea, ${ }^{a}$ Jianbing Jiang, ${ }^{a}$ Jos Reijngoud, ${ }^{C}$ \\ Arthur F. J. Ram, ${ }^{C}$ Gilles P. van Wezel, (D) ${ }^{c}$ Gijsbert A. van der Marel, ${ }^{a}$ \\ Jeroen D. C. Codée, (D) ${ }^{a}$ Herman S. Overkleeft (DD ${ }^{* a}$ and Gideon J. Davies (D)*b
}

\begin{abstract}
Cellulases and related $\beta$-1,4-glucanases are essential components of lignocellulose-degrading enzyme mixtures. The detection of $\beta-1,4$-glucanase activity typically relies on monitoring the breakdown of purified lignocellulose-derived substrates or synthetic chromogenic substrates, limiting the activities which can be detected and complicating the tracing of activity back to specific components within complex enzyme mixtures. As a tool for the rapid detection and identification of $\beta$-1,4-glucanases, a series of glycosylated cyclophellitol inhibitors mimicking $\beta$-1,4-glucan oligosaccharides have been synthesised. These compounds are highly efficient inhibitors of HiCel7B, a well-known GH7 endo- $\beta-1,4-$ glucanase. An elaborated activity-based probe facilitated the direct detection and identification of $\beta$-1,4-glucanases within a complex fungal secretome without any detectable cross-reactivity with $\beta$-D-glucosidases. These probes and inhibitors add valuable new capacity to the growing toolbox of cyclophellitol-derived probes for the activity-based profiling of biomass-degrading enzymes.
\end{abstract}

\section{Introduction}

Activity-based protein profiling (ABPP) is a powerful technique used to detect and identify active enzymes using modified covalent inhibitors. Following early successes in the detection and identification of proteases, ${ }^{1}$ this technique has been extended to glycoside hydrolases using a variety of strategies, ${ }^{2,3}$ including labelled cyclophellitol derivatives. ${ }^{4}$

Though often considered synonymous with cellulases, $\beta-1,4$ glucanases are enzymes which recognize $\beta$-1,4-linked glucan chains which are characteristic of both the cellulosic and hemicellulosic (i.e. mixed-linkage glucans, xyloglucans, and glucomannans) fractions of plant biomass. ${ }^{5}$ The catalytic actions of a variety of retaining $\beta$-1,4-glucanases contribute to the breakdown of lignocellulosic polysaccharides. ${ }^{6,7}$ The efficient and specific profiling of $\beta-1,4$-glucanases is thus a valuable tool in the study of biomass-degrading organisms.

\footnotetext{
${ }^{a}$ Leiden Institute of Chemistry, Leiden University, Einsteinweg 55, 2300 RA Leiden, The Netherlands. E-mail: h.s.overkleeft@chem.leidenuniv.nl

${ }^{b}$ York Structural Biology Laboratory, Department of Chemistry, The University of York, Heslington, York, YO10 5DD, UK. E-mail: Gideon.davies@york.ac.uk ${ }^{c}$ Institute of Biology Leiden, Leiden University, Sylviusweg 72, 2333 BE Leiden, The Netherlands

$\dagger$ Electronic supplementary information (ESI) available: Supplemental figures and table, supplementary synthetic protocols and characterisation. See DOI: $10.1039 /$ docb00045k

\$ These authors contributed equally to this work.
}

Efforts have been made to profile $\beta$-1,4-glycanases using different "warhead" chemistries. Activity-based probes (ABPs) based on a 2,4-dinitrophenyl 2-deoxy-2-fluoro- $\beta$-xylobioside/ cellobioside modified with an affinity tag at the 4 ' position proved effective probes for retaining $\beta$-D-glucanases and $\beta$-xylanases with particularly good specificity. ${ }^{2,8,9}$ However, the slow hydrolysis of the enzyme-probe complex and the weak initial binding of these probes necessitated the use of high probe concentration $(\sim 0.5-1 \mathrm{mM})$ and time-limited labelling for ABPP. Later experiments using difluoromethylphenyl glycosides and $N$-haloacetyl glycosylamines demonstrated a unique capacity to label inverting glycoside hydrolases, but suffered from significant non-specific labelling. ${ }^{3}$

Cyclophellitol is an inhibitor of $\beta$-D-glucosidases originally isolated from the Phellinus mushroom. ${ }^{10}$ This cyclitol is an isostere of a glucoside where the acetal group is replaced by an epoxide. Taking advantage of the catalytic machinery of a retaining glycoside hydrolase, this epoxide undergoes an acid-catalysed ring opening addition to form a non-hydrolysable ester in place of the normal glycosylenzyme intermediate, irreversibly inactivating the enzyme. ${ }^{11}$

ABPs built around synthetic cyclitols, having configurations which target $\alpha$ - and $\beta$-D-glucosidases, ${ }^{12-14} \beta$-D-glucuronidases, ${ }^{15}$ $\beta$-D-xylosidases, ${ }^{16} \alpha$ - and $\beta$-D-galactosidases, ${ }^{17,18}$ and $\alpha$-L-arabinofuranosidases, ${ }^{19}$ among others, have consistently been shown to covalently modify the catalytic nucleophiles of cognate retaining glycosidases. These cyclophellitol-derived ABPs generally bind with good specificity, high affinity, and complete irreversibility. 
Recent work has shown that cyclophellitol derivatives can be glycosylated, enabling the development of inhibitors and probes which react specifically with endo-glycanases. ${ }^{16}$ This was first demonstrated with the development of an inhibitor and a collection of ABPs for $\beta-1,4$-xylanases. Being built around a xylobiose core with an alkylated aziridine warhead, these probes proved to be potent covalent inhibitors of GH10 $\beta-1,4$ xylanases, but showed cross-reactivity with $\beta$-D-xylosidases when applied to the direct detection of $\beta$-xylanases within fungal secretomes. This cross-reactivity was traced back to the internal hydrolysis of the probe by the action of $\beta$-D-xylosidases.

Building on this understanding, here we report the development of cyclophellitol-derived ABPs designed to target $\beta-1,4$ glucanases, some of the most abundant glycoside hydrolases in nature. To detect and profile these enzymes, a collection of 4-O substituted (carbohydrate numbering) cyclophellitols have been synthesised and tested for their ability to covalently modify HiCel7B, a well-known endo- $\beta$-1,4-glucanase. Through biochemical, structural, and mass spectrometric analyses, we have identified a potent substrate-mimicking probe architecture which shows resistance to hydrolysis by exo-glucosidase and endo-glucanase activities within a fungal secretome.

\section{Experimental}

\section{Synthesis of $\beta$-D-glucanase inhibitors and probe}

Chemical synthesis details and compound analysis is reported in the ESI. $\dagger$

\section{Testing $\beta$-D-glucanase inhibitors and probes}

HiCel7B was a kind gift from Martin Schülein (sadly now deceased) at Novozymes A/S (Lyngby, Denmark). The pH-activity profile of HiCel7B acting on 4-methylumbelliferyl $\beta$-D-cellobioside (4MU-GG) was measured by combining $5 \mu \mathrm{L}$ of $1 \mu \mathrm{g} \mathrm{mL}^{-1}$ HiCel7B in 200 mM 2:7:7 succinate-phosphate-glycine (SPG) buffer prepared at various $\mathrm{pH}$ values with $45 \mu \mathrm{L}$ of $0.1 \mathrm{mM}$ substrate in quadruplicate. The reactions were incubated at $25{ }^{\circ} \mathrm{C}$ for 30 minutes prior to the addition of $5 \mu \mathrm{L}$ of $1 \mathrm{M} \mathrm{Na}_{2} \mathrm{CO}_{3}$, transfer of $50 \mu \mathrm{L}$ to a black 384-well plate and fluorescence measurement $\left(\lambda_{\mathrm{ex}}=360 \mathrm{~nm}, \lambda_{\mathrm{em}}=450 \mathrm{~nm}\right)$. Rates were determined using a 4-methylumbelliferone calibration series prepared in $0.1 \mathrm{M} \mathrm{Na}_{2} \mathrm{CO}_{3}$.

Intact $\mathrm{MS}$ of HiCel7B bound to different inhibitors was performed according to McGregor et al. ${ }^{19}$ Briefly, enzyme was diluted to $0.1 \mathrm{mg} \mathrm{mL}^{-1}(\sim 2.2 \mu \mathrm{M})$ in $20 \mathrm{mM}$ sodium phosphate buffer $\mathrm{pH}$ 7. Compounds $\mathbf{1}, \mathbf{5}$, or $\mathbf{1 3}$ were added to a final concentration of $5 \mu \mathrm{M}$ and incubated at $25{ }^{\circ} \mathrm{C}$. Samples taken at 1 hour were diluted with 4 volumes of $1 \%$ formic acid, $10 \%$ acetonitrile and analysed. Additional experiments with 5 were performed using different concentrations of inhibitor and enzyme as indicated in the text.

Inhibition kinetics for compounds 1, 5, and 13 acting on HiCel7B were measured at $25{ }^{\circ} \mathrm{C}$ using $4 \mathrm{MU}-\mathrm{GG}$ following a method described previously. ${ }^{19}$ Briefly, enzyme was diluted in $50 \mathrm{mM}$ sodium phosphate buffer $\mathrm{pH}$ 7. Substrate was dissolved
Table 1 Kinetic parameters for covalent inhibition of HiCel7B by putative $\beta$-1,4-glucanase inhibitors

\begin{tabular}{lcll}
\hline & HiCel7B & \\
\cline { 2 - 4 } Compound & $K_{\mathrm{I}}(\mu \mathrm{M})$ & $k_{\text {inact }}\left(\mathrm{min}^{-1}\right)$ & $k_{\text {inact }} / K_{\mathrm{I}}\left(\mathrm{s}^{-1} \mathrm{M}^{-1}\right)$ \\
\hline $\mathbf{1}$ & $31 \pm 4$ & $0.84 \pm 0.08$ & 450 \\
$\mathbf{5}$ & $1.9 \pm 0.3$ & $0.35 \pm 0.03$ & 3100 \\
$\mathbf{1 3}$ & $3.9 \pm 0.3$ & $0.50 \pm 0.03$ & 2100
\end{tabular}

in DMSO to give a $10 \mathrm{mM}$ stock which was diluted with ultrapure water. Inhibitors were dissolved in and diluted with ultrapure water with the exception of $\mathbf{1 3}$ which was dissolved in DMSO to give a $5 \mathrm{mM}$ stock which was diluted with ultrapure water. The enzyme and substrate concentrations used in the continuous inhibition assays were $10 \mathrm{ng} \mathrm{mL}^{-1}(\sim 220 \mathrm{pM})$ and $50 \mu \mathrm{M}$, respectively. The $K_{\mathrm{M}}$ value for the interaction of HiCel7B with 4MU-GG under the assay conditions (corrected for inner filter effect) was measured to be $76 \mu \mathrm{M}$ (Fig. S1, ESI $\dagger$ ) and this was used as a correction factor to determine the $K_{\mathrm{I}}$ values in Table 1 from the apparent $K_{\mathrm{I}}$ determined from fitting of $k_{\text {app }} v s$. [inhibitor] curves.

\section{Enzyme crystallisation, diffraction, and structure solution}

Deglycosylated HiCel7B was desalted into $20 \mathrm{mM}$ pH 8 Tris- $\mathrm{HCl}$ buffer and concentrated to $12 \mathrm{mg} \mathrm{mL}^{-1}$ using a $30 \mathrm{kDa}$ MWCO centricon. Building on previous reports, ${ }^{20,21}$ crystallisation conditions were re-screened using the PACT Suite and AmSO4 Suite (Qiagen) crystallisation screens. High quality tetragonal bipyramidal crystals grew consistently at $20{ }^{\circ} \mathrm{C}$ from a $2: 1$ mixture of protein solution:well solution, where well solution was $0.15 \mathrm{M}$ sodium citrate, $0.8 \mathrm{M}$ ammonium sulfate, $1 \mathrm{M}$ lithium sulfate (Fig. S2, ESI $\dagger$ ). Crystal soaks were performed in a solution composed of $0.1 \mathrm{mM}$ ligand in mother liquor for 5 hours at $20{ }^{\circ} \mathrm{C}$ prior to transfer into mother liquor supplemented with $20 \%$ glycerol and cryo-cooling in $\mathrm{LN}_{2}$.

Crystals were diffracted at Diamond Light Source (Harwell, UK) on beamline I03 at a wavelength of $0.9762 \AA$ and automatically processed using the $\mathrm{Xia}^{22}$ pipeline with 3 dii. Computation was carried out using programs from the CCP4 suite ${ }^{23}$ unless otherwise stated. All crystal structure figures were generated using Pymol (Schrodinger). Data collection and processing statistics for all structures are given in Table S1 (ESI $\dagger$ ).

Data for HiCel7B bound to compound 1 were collected to $1.88 \AA$ A. Data were also collected out to $1.2 \AA$ in a higher space group $\left(P 4_{2} 2_{1} 2\right)$ following a soak with 13 , though the structure was found to be unliganded. The structure of 1-bound HiCel7B was solved in the $P 4_{1} 22$ space group by molecular replacement using Phaser ${ }^{24}$ with the known structure (PDBID: 2A39) as the search model. Ligand 1 was built using the existing restrains for $\beta$-D-glucose (BGC) and cyclophellitol (YLL) with Coot, ${ }^{25}$ and structures were refined by alternating rounds of manual model building and density refinement using Coot and REFMAC5 ${ }^{26}$ respectively.

\section{In-gel fluorescence}

The $\mathrm{pH}$-labelling profile of HiCel7B reacting with the probe was measured by combining $10 \mu \mathrm{L}$ of $1 \mu \mathrm{g} \mathrm{mL} \mathrm{m}^{-1} \mathrm{HiCel7B}$ in $200 \mathrm{mM}$ 
SPG buffer prepared at various pH values with $10 \mu \mathrm{L}$ of $10 \mu \mathrm{M}$ 14 in quadruplicate. The reactions were incubated at $25{ }^{\circ} \mathrm{C}$ for 10 minutes prior to the addition of $8 \mu \mathrm{L}$ of $4 \times$ SDS-PAGE loading dye and heating to $95{ }^{\circ} \mathrm{C}$ for 2 minutes. $10 \mu \mathrm{L}$ of each reaction was separated on a $10 \%$ SDS-PAGE gel prior imaging using the Cy5 laser/filter settings on a Typhoon 5 scanner (GE Healthcare). Bands were integrated using ImageQuant (GE Healthcare).

Secretome staining was performed using two aliquots of $20 \mu \mathrm{L}$ xylan-grown Aspergillus niger secretome (day 4 samples prepared as described previously $\left.{ }^{16}\right)$. To each was added $5 \mu \mathrm{L}$ of $0.5 \mathrm{M}$ pH 5 McIlvane buffer. To one was then added $5 \mu \mathrm{L}$ of $60 \mu \mathrm{M} 14$ and to the other was added $5 \mu \mathrm{L}$ of $60 \mu \mathrm{M} 19(10 \mu \mathrm{M}$ final ABP concentration). These were incubated for 30 minutes at $37{ }^{\circ} \mathrm{C}$. The reactions were then split in two and one half $(15 \mu \mathrm{L})$ was diluted with $5 \mu \mathrm{L}$ of water. The other half $(15 \mu \mathrm{L})$ of the reaction with 19 was then supplemented with $5 \mu \mathrm{L}$ of $40 \mu \mathrm{M}$ 14 and the other half of the reaction with $\mathbf{1 4}$ was supplemented with $5 \mu \mathrm{L}$ of $40 \mu \mathrm{M} 19(10 \mu \mathrm{M}$ final ABP concentration). The reactions were incubated for a further 30 minutes at $37{ }^{\circ} \mathrm{C}$ before being diluted with $8 \mu \mathrm{L}$ of $4 \times$ SDS-PAGE loading dye, separated on a $4-20 \%$ SDS-PAGE gel (Bio-Rad) and imaged for fluorescence using the Cy2 and Cy5 laser/filter settings on a Typhoon 5 scanner (GE Healthcare).

\section{Biotin-avidin enrichment proteomic analysis}

5 aliquots of $1 \mathrm{~mL}$ of xylan-grown Aspergillus niger secretome were thawed from $-80{ }^{\circ} \mathrm{C}$, centrifuged at $12000 \times g$ for 15 minutes to remove particulate and combined. $0.5 \mathrm{~mL}$ of this was then subsampled into 9 separate Lo-Bind $2.0 \mathrm{~mL}$ tubes. To three tubes was added $55 \mu \mathrm{L}$ of $1 \mathrm{mM}$ compound 1 in ultrapure water, and to the rest $55 \mu \mathrm{L}$ of ultrapure water. All samples were incubated for 1 hour at $37{ }^{\circ} \mathrm{C}$ prior to the addition of $60 \mu \mathrm{L}$ of compound 15 in $10 \%$ DMSO to the samples treated with 1 and three of the samples not treated with 1. 10\% DMSO was added to the remaining three samples. All of the samples were incubated for a further 2 hours at $37{ }^{\circ} \mathrm{C}$. Proteins were denatured by heating to $95{ }^{\circ} \mathrm{C}$ for 5 minutes following the addition of $70 \mu \mathrm{L}$ of $10 \times$ denaturing buffer (500 mM Na-HEPES, pH 7.5, 50 mM DTT, 5\% SDS). Once cooled to RT, thiols were alkylated by the addition of $70 \mu \mathrm{L}$ of $0.25 \mathrm{M}$ iodoacetamide and incubation in the dark for 30 minutes. Samples were transferred to $5 \mathrm{~mL}$ Eppendorf tubes and proteins were precipitated by the addition of $3.2 \mathrm{~mL}$ of chilled acetone followed by incubation at $-20{ }^{\circ} \mathrm{C}$ for 1 hour. Proteins were collected by centrifugation $(14000 \times g$ for 1 minute) and the supernatant was discarded. The pellet was washed with $3 \mathrm{~mL}$ of cold acetone and air-dried. The pellet was then resuspended in $50 \mu \mathrm{L}$ of $8 \mathrm{M}$ urea, $10 \mathrm{mM}$ HEPES, pH 7.2 and diluted with $150 \mu \mathrm{L}$ of $0.05 \%$ SDS in phosphate-buffered saline (PBS). This was shaken overnight at $20{ }^{\circ} \mathrm{C}$ to dissolve. The samples were then diluted with a further $200 \mu \mathrm{L}$ of $0.05 \%$ SDS in PBS and centrifuged to collect any insoluble residue. The supernatant was transferred to a $2 \mathrm{~mL}$ Eppendorf tube and mixed with $25 \mu \mathrm{L}$ of Pierce Avidin Agarose beads (Thermo Fisher Scientific) which had been washed twice with PBS. Following 3 hours of mixing by inversion, beads were collected by centrifugation for 2 minutes at
$2500 \times g$. The supernatant was removed and the beads were washed with $500 \mu \mathrm{L}$ of $0.5 \%$ SDS in PBS once, $500 \mu \mathrm{L}$ of $2 \%$ SDS at $65{ }^{\circ} \mathrm{C}$ for 10 minutes once, $500 \mu \mathrm{L}$ of $0.5 \%$ SDS in PBS again, then $500 \mu \mathrm{L}$ of $2 \mathrm{M}$ urea followed by two washes with $500 \mu \mathrm{L}$ of ultrapure water. The beads were finally resuspended in $20 \mu \mathrm{L}$ of on-bead digestion buffer and trypsinisation, StageTip desalting, LC-MS/MS data acquisition, and data processing were performed as described previously. ${ }^{27}$ Peptides were identified by searching against a database of $A$. niger NRRL3 proteins ${ }^{28}$ supplemented with streptavidin, avidin, yeast enolase and trypsin. The combined search results were filtered for a minimum of two unique peptides with a false-discovery rate of $4 \%$. Label-free quantification was performed using Progenesis QI (Waters). Following chromatographic alignment, peaks were integrated and assigned. Protein abundance was estimated using the integrated intensity of nonconflicting peptides. Results of this analysis for all identified proteins can be found in Table S2 ( $\mathrm{ESI} \dagger)$.

\section{Results and discussion}

\section{Synthesis of potential cellulase inhibitors and probes}

Cellobiose configured cyclophellitol (1) was synthesized via previously reported procedures. ${ }^{16}$ Glycosylation of cyclophellitol acceptor 2 with cellobiose-derived $N$-phenyl trifluoroacetimidate 3 afforded pseudo-trisaccharide 4 (Scheme 1). The deprotection sequence: benzoyl removal by $\mathrm{NaOMe}$ in $\mathrm{MeOH}$, followed by short hydrogenation over a high loading of Pearlman's catalyst, ${ }^{29}$ yielded inhibitor 5 .

To gain access to cellobiose configured ABPs 4-deoxy-4-azidothioglucoside donor 9 was synthesized. The methods are similar to a published synthesis of 4-deoxy-4-fluoro-thioglucoside donors. ${ }^{30}$ The axial 4 -OH of partially protected methyl $\alpha$-D-galactopyranoside 6 was activated as a triflate and substituted by sodium azide leading to 7. Acid-catalyzed displacement of the anomeric methoxy group afforded anomeric acetate 8. Introduction of the anomeric thiophenol yielded donor 9.

The glycosylation reaction was improved, compared to that employed in the inhibitor synthesis. Application of a preactivation protocol $\left(\mathrm{Tf}_{2} \mathrm{O} / \mathrm{Ph}_{2} \mathrm{SO}\right)$ circumvents the use of relatively high temperatures and long reaction times required to activate this type of donor using NIS/TfOH. It also allows the activation of the donor to take place without the presence of the acid-labile epoxide. Disaccharide 10 was obtained in $64 \%$ yield without the use of a large excess of donor. Unreacted acceptor (2) was also recovered indicating the stability of the epoxide functionality under these conditions. Increasing the amount of donor (9) led to diminished yield and complex mixtures. This was presumably due to the reaction of the epoxide in the product with the excess activated donor. ${ }^{31}$

Following the synthesis of disaccharide 10, the benzoyl esters were removed with NaOMe affording 11. Staudinger reduction of the azide followed by benzyl removal under Birch conditions afforded fully deprotected $\mathbf{1 2}$.

Azide-terminated triethylene glycol $t$-butyl ester $\mathbf{1 6}^{32}$ was deprotected using trifluoroactic acid and DIC/DMAP mediated 

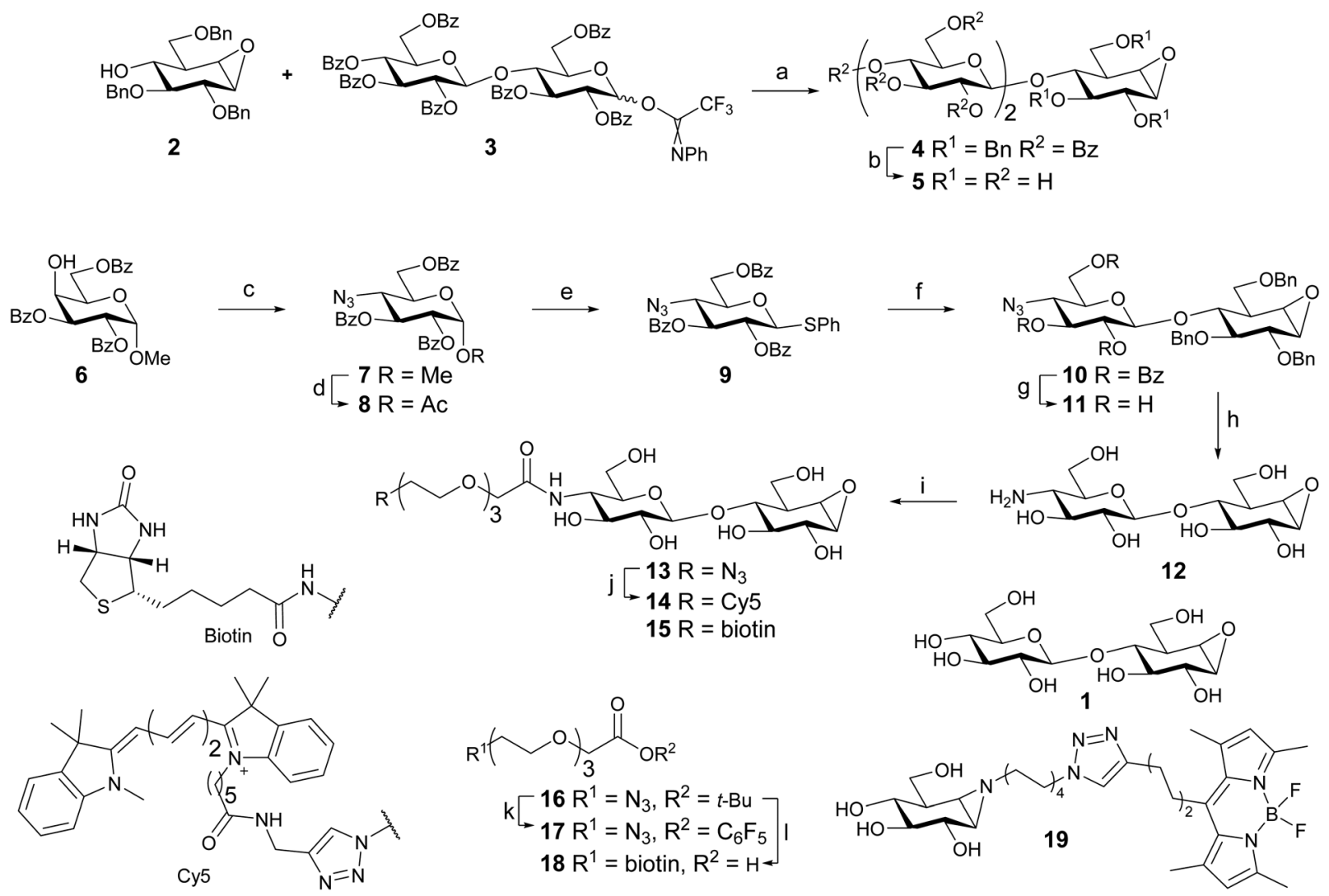

Scheme 1 Reagent and conditions: (a) TSMOTf, DCM, $-15^{\circ} \mathrm{C}$ to $0{ }^{\circ} \mathrm{C}, 45 \%$. (b) (i) $\mathrm{NaOMe}, \mathrm{MeOH}$. (ii) $\mathrm{H}_{2}, \mathrm{Pd}(\mathrm{OH})_{2} / \mathrm{C}, \mathrm{H}_{2} \mathrm{O}, \mathrm{MeOH}$, dioxane, $40 \%$. (c) (i) Tf $2 \mathrm{O}$, pyr, $\mathrm{DCM},-55^{\circ} \mathrm{C}$ to rt. (ii) $\mathrm{NaN}_{3}, \mathrm{DMF}, 80^{\circ} \mathrm{C}, 90 \%$. (d) $\mathrm{Ac}_{2} \mathrm{O}, \mathrm{AcOH}, \mathrm{H}_{2} \mathrm{SO}_{4}$. (e) $\mathrm{HSPh}, \mathrm{BF}_{3} \cdot \mathrm{Et}_{2} \mathrm{O}, \mathrm{DCM}, 46 \%$ over 2 steps. (f) $2, \mathrm{Ph}_{2} \mathrm{SO}, \mathrm{Tf}_{2} \mathrm{O}, \mathrm{TTBP}^{\circ}, \mathrm{DCM},-70{ }^{\circ} \mathrm{C}$ to rt, 64\%. (g) $\mathrm{NaOMe}, \mathrm{MeOH}, \mathrm{DCM}, 60 \%$. (h) $\mathrm{Na}$ (s), $t-\mathrm{BuOH}, \mathrm{NH}_{3},-60{ }^{\circ} \mathrm{C}, 53 \%$. (i) 17, DIPEA, DMF, 27\%; or 18, PFPOH, DIC, Et $3 \mathrm{~N}, \mathrm{DMF}, 44 \%$. (j) $\mathrm{Cy} 5$ alkyne, THPTA, Cul, DIPEA, DMSO, 46\%. (k) (i) TFA, DCM; (ii) PFPOH, DIC, DMAP, DCM, 67\%. (l) (i) $\mathrm{PPh}_{3}, \mathrm{H}_{2} \mathrm{O}, \mathrm{THF}, 88 \%$; (ii) BiotinNHS, DIPEA, DMF, 83\%; (iii) TFA, DCM, quant.

esterification with pentafluorophenol afforded activated ester 17. The amine in $\mathbf{1 2}$ was selectively acylated with 17, yielding probe 13 following semi-preparative HPLC purification. Cy5-labeled probe $\mathbf{1 4}$ was obtained after copper catalyzed click reaction of $\mathbf{1 3}$ with Cy5 alkyne. Biotin-labeled probe $\mathbf{1 5}$ was synthesized in one step from 12 by amide bond formation with biotin-terminated spacer 18, obtained from 16 in 3 steps.

BODIPY green-labeled $\beta$-glucosidase probe 19 was obtained by methods developed for the previously reported BODIPY red variant using BODIPY green alkyne. ${ }^{33,34}$

\section{Testing potential cellulase inhibitors and probes with HiCel7B}

Humicola insolens Cel7B (HiCel7B) was chosen as a model $\beta$-D-glucanase since it is well-characterized, has good hydrolytic performance with chromogenic substrates, can be readily crystallised, and has been studied in our lab previously. ${ }^{20,21,35}$

Compound 1 proved to be an efficient covalent inhibitor of HiCel7B, with a $k_{\mathrm{i}} / K_{\mathrm{I}}$ of $450 \mathrm{M}^{-1} \mathrm{~s}^{-1}$ (Fig. 1 and Table 1$)$. Intact MS confirmed complete, single labelling after 60 minutes at $25{ }^{\circ} \mathrm{C}$ (Fig. 2A). These kinetics compare favourably with the reported requirement to incubate $F$. oxysporum EG I with $8.25 \mathrm{mmol}$ of 3,4-epoxybutyl $\beta$-D-cellobioside for 3 hours at $40{ }^{\circ} \mathrm{C}$ to achieve complete inhibition. ${ }^{36}$
The addition of another $\beta$-1,4-linked glucose residue to the non-reducing terminus to give 5 improved the performance of the inhibitor roughly 7-fold (Table 1 and Fig. S3, ESI $\dagger$ ), however intact MS with $2.2 \mu \mathrm{M}$ enzyme and $5 \mu \mathrm{M}$ inhibitor revealed minimal labelling (Fig. S4, ESI $\dagger$ ). Treatment with 5 gave small peaks with mass differences of both $\sim 338$ Da (equivalent to addition of 1) and $\sim 500 \mathrm{Da}$ (expected). Soaking HiCel7B crystals with $0.1 \mathrm{mM} 5$ also gave an unliganded enzyme structure. Repeating the intact MS experiment with a higher inhibitor concentration $(50 \mu \mathrm{M})$ resulted in more overall labelling, but still a dominant mass difference of $\sim 338 \mathrm{Da}$. Lowering the inhibitor $(5 \mu \mathrm{M})$ and enzyme concentrations $(0.5 \mu \mathrm{M})$ gave overall weaker signal, showing incomplete labelling, with a mass difference attributable to $\mathbf{5}$ as the dominant modification (Fig. S4, ESI $\dagger$ ). We interpret these results as indicative of an internal hydrolysis of $\mathbf{5}$ to give primarily a mixture of cellobiose and cyclophellitol, which is unreactive, and secondarily a mixture of $\mathbf{1}$ and glucose, which gives rise to the smaller observed mass difference. The observed concentration-dependence suggests that both hydrolytic processes have a higher $K_{\mathrm{M}}$ than the $K_{\mathrm{I}}$ of the interaction between HiCel7B and 5. Thus, the course of inhibition of HiCel7B with $\mathbf{5}$ is enzyme- and inhibitor concentration-dependent, being affected by the $K_{\mathrm{M}}$ of the two possible hydrolytic pathways and the $K_{\mathrm{I}}$ values for 5 and $\mathbf{1}$. 
A

To hopefully avoid the complication of internal hydrolysis, 13

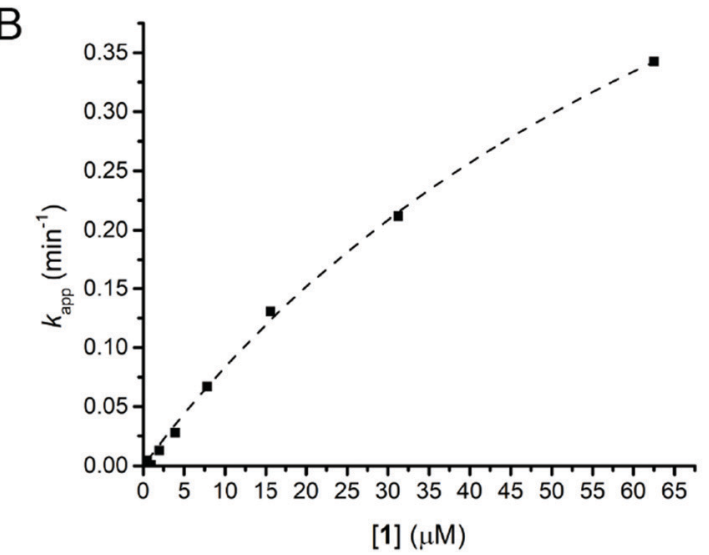

Fig. 1 HiCel7B inhibition kinetics with inhibitor 1. (A) Plot of fluorescence vs. time for HiCel7B in the presence of different concentrations of inhibitor 1. Each line represents a single measurement. (B) Plot of apparent decay constant $\left(k_{\text {app }}\right)$ extracted from an exponential decay fit of the curves shown in panel A vs. inhibitor concentration with the hyperbolic fit shown as a dotted line. Each point is the average of two measurements.
Probe 13 turned out to be a strong inhibitor of HiCel7B, reacting with a $k_{\mathrm{i}} / K_{\mathrm{I}}$ of $2100 \mathrm{M}^{-1} \mathrm{~s}^{-1}$, comparable to that of the 5. Intact MS confirmed complete single labelling at a 5:2.2 probe : enzyme stoichiometric ratio (Fig. S4, ESI $\dagger$ ), confirming efficient labelling without hydrolysis. Modifying the azide handle of 13 with Cy5 gave compound 14, which is an effective probe for in-gel fluorescence-based detection of HiCel7B. A serial dilution of HiCel7B with 14 gave significant signal for the HiCel7B band from as little as $1.6 \mathrm{pg}$ of enzyme per well (Fig. S5, ESI $\dagger$ ). Probe 14 also facilitated measurement of the pH-labelling profile for HiCel7B (Fig. S6A, ESI $\dagger$ ). Comparison to the $\mathrm{pH}$-activity profile for the hydrolysis of $4 \mathrm{MU}-\mathrm{GG}$ shows significant similarity between the pH-labelling profile and pH-activity profile, particularly above pH 5 (Fig. S6B, ESI $\dagger$ ).

\section{was built on a $\beta-1,4$-glucosyl cyclophellitol inhibitor core.}

\section{The structure of the HiCel7B complex with inhibitor 1}

Soaking HiCel7B crystals with 1 yielded the complex shown in Fig. 2B. This confirmed that $\mathbf{1}$ binds in the expected manner, mimicking the ${ }^{4} \mathrm{C}_{1}$ conformation of two glucose units of cellobiose previously observed in the -1 and -2 subsites (Fig. 2C). ${ }^{37}$ Binding of the inhibitor had no significant impact on the structure of the active site, inducing no conformational change following addition to the catalytic nucleophile. This is in spite of the epoxide oxygen forming an extremely close $(2.3 \AA)$ contact with the general acid/base. Extending beyond the -2 subsite, in which essential hydrophobic stacking with W347 and hydrogen bonding interactions with R108, Y147, and S345 are formed, the active site broadens significantly, suggesting a lack of a specific -3 subsite, possibly accounting for the weak selectivity between 5 and 13.

\section{Enzyme detection and identification by in-gel fluorescence and biotin-avidin enrichment}

To test the ability of the probe to stain $\beta$-D-glucanases in fungal secretomes without staining $\beta$-D-glucosidases, an A. niger xylangrown secretome was stained with 14 or 19, followed by 19 or
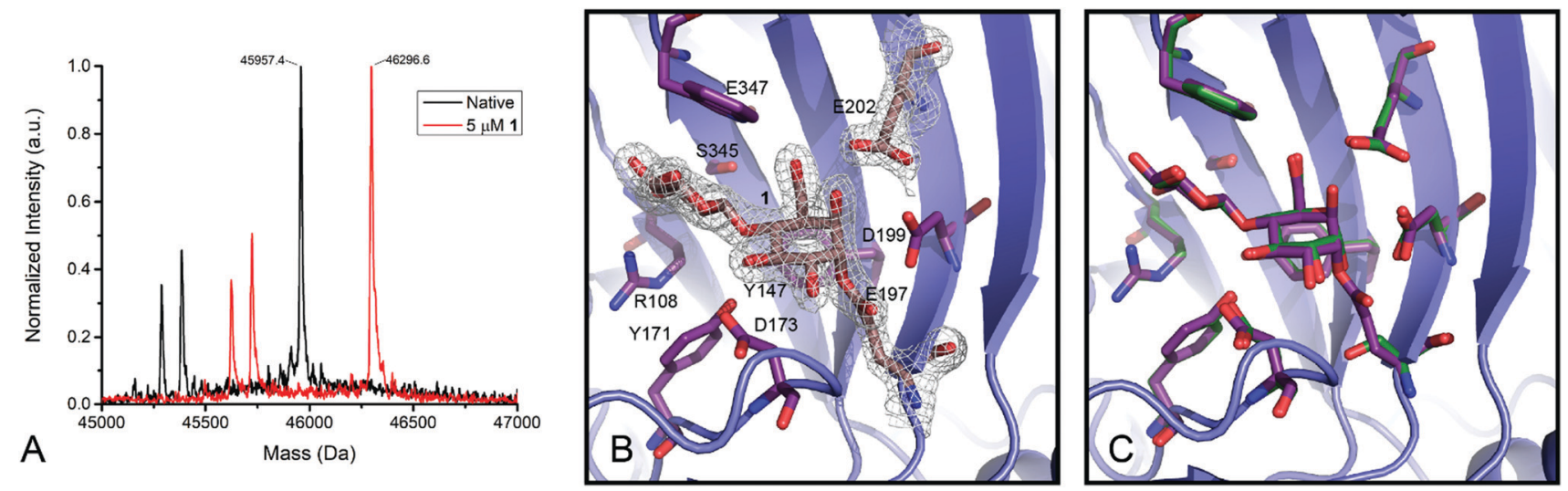

Fig. 2 Labelling of HiCel7B with 1. (A) Deconvoluted intact mass spectra of HiCel7B with (red) and without (black) incubation with 1. $\Delta \mathrm{m}$ (expected) = $338, \Delta m$ (observed) $=339$. (B) Structure of the HiCel7B:1 complex showing $2 F_{\mathrm{o}}-F_{\mathrm{c}}$ electron density at $2 \sigma$. Amino acids having polar or hydrophobic contacts with 1 are shown as purple sticks, 1, E197, and E202 are shown as tan sticks. (C) Overlay of 1 complex with Cellobiose:HiCel7B(E197S) complex (PDB ID: 1OJK). Active site residues and cellobiose from PDB ID 1OJK are shown in green, active site residues and 1 from PDB ID 6 YOZ (this work) are shown in purple. 
A

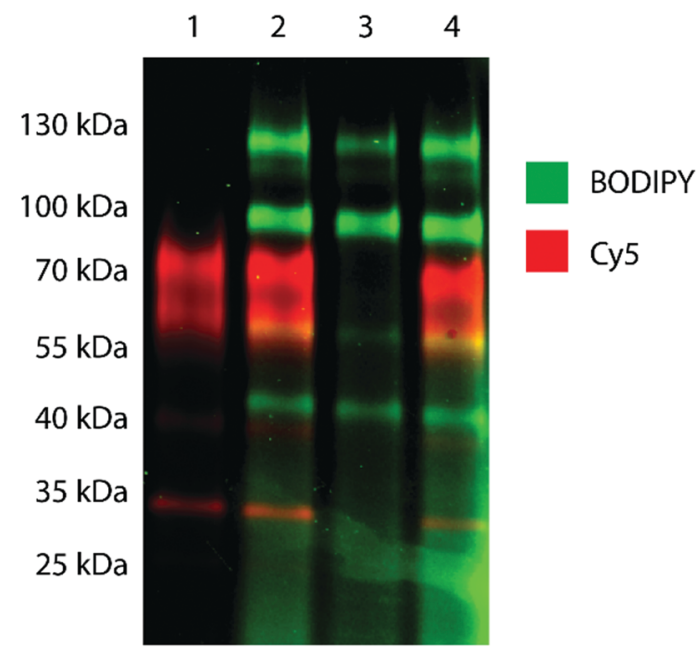

B

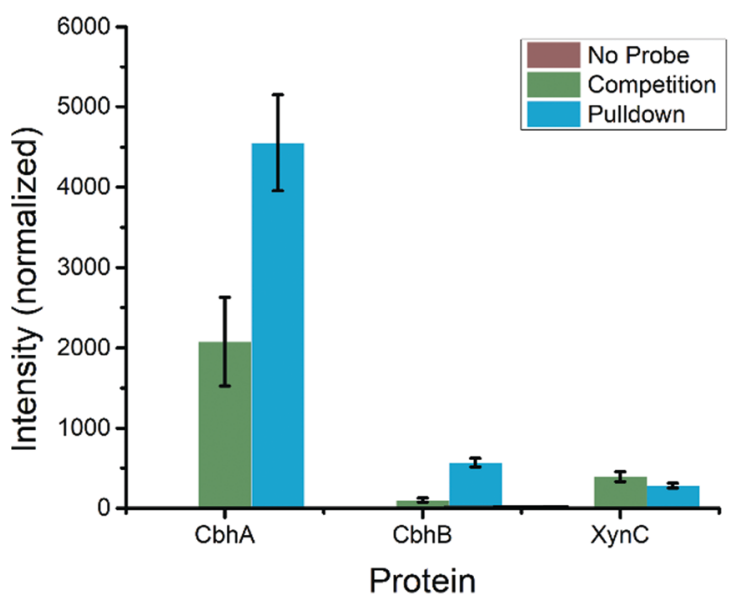

Fig. 3 (A) Staining of the A. niger xylan-grown secretome with 14 and 19 Dual channel fluorescence scan of a $4-20 \%$ SDS-PAGE is shown. Lane 1 contains 14-stained secretome, lane 2 contains 14-stained secretome subsequently stained with 19 , lane 3 contained 19 -stained secretome, and lane 4 contains 19-stained secretome subsequently stained with 14 . (B) Label-free quantification of proteins identified from the $A$. niger secretome following treatment with probe 15 and biotin-avidin enrichment. The "No Probe" sample is the negative control, the "Competition" sample was pre-treated with inhibitor 1 , and the "Pulldown" sample was only treated with probe 15 . The observed signal intensity was normalised

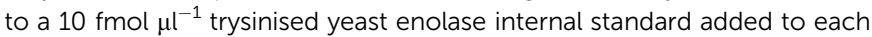
sample prior to analysis.

14, respectively (Fig. 3A). 19-stained bands were present at molecular weights of $\sim 45 \mathrm{kDa}, \sim 60 \mathrm{kDa}, \sim 100 \mathrm{kDa}$, and $\sim 130 \mathrm{kDa}$. 14-stained bands were present at $\sim 35 \mathrm{kDa}$, $\sim 40 \mathrm{kDa}$ (faint), $\sim 60$, and $\sim 80 \mathrm{kDa}$. Notably, the gel shows minimal overlap between the staining of the two probes and no apparent preclusion of staining of one probe by the other. This suggests that among the retaining glycoside hydrolases secreted by A. niger, there is no hydrolysis of $\mathbf{1 4}$ and no crossreactivity between 14 and 19. Thus, 4-O substitution appears to reduce cross-reactivity with exo-glycosidases compared to the previously reported xylanase probes. ${ }^{16}$

Based on the known content of this secretome, we tentatively assigned the 60 and $80 \mathrm{kDa}$ 14-stained bands as CbhA and CbhB respectively, two $\mathrm{GH} 7$ cellulases. ${ }^{39} \mathrm{We}$ also assigned the $\sim 40 \mathrm{kDa}$ band as EglB, ${ }^{40}$ a GH5 endo- $\beta$-D-glucanase, and the $\sim 35 \mathrm{kDa}$ band as XynC, an abundant GH10 xylanase likely stained due to a loose enzyme-substrate specificity comparable to other fungal GH10 xylanases. ${ }^{41,42}$ We tentatively assign the 100 and $130 \mathrm{kDa}$ 19-stained bands as GH3 enzymes, possibly BglA, BglM, and $\mathrm{XlnD},{ }^{38}$ which have been detected in this secretome previously. ${ }^{16}$

To test the specificity of our cellulase probe architecture, we used the biotinylated derivative (probe 15) and performed a biotin-avidin pulldown enrichment prior to on-bead digestion, peptide identification, and label-free quantification. Three samples were prepared: a negative control, a probe 15-treated sample, and a sample treated with probe $\mathbf{1 5}$ after treatment with inhibitor $\mathbf{1}$. The only proteins from $A$. niger detected at elevated levels in the probe 15-treated samples relative to the negative control were CbhA, $\mathrm{CbhB}$, and XynC, confirming our assignment of the major bands observed by in-gel fluorescence. Label-free quantification showed a significant drop in CbhA and CbhB signal following treatment with inhibitor 1 , but revealed no significant drop in XynC signal, suggesting that XynC was minimally inhibited (Fig. 3B). Thus, the probe architecture presented here shows specificity towards known GH7 cellulases within the context of a complex fungal secretome.

\section{Conclusions}

$\beta-1,4-G l u c a n a s e s$ form the foundations of lignocellulose-degrading systems. Being produced by a wide variety of saprotrophic, symbiotic, and pathogenic microorganisms, the ability to detect small quantities of these enzymes directly offers a variety of opportunities for activity-based protein profiling. We have shown here that a cellobiose-mimicking cyclophellitol derivative is a potent inhibitor of $\beta-1,4$-glucanases. We have also shown that extension of this inhibitor from the $4^{\prime}$ position with glucose enhances inhibitor binding, but facilitates inhibitor hydrolysis. Fortuitously, extension with a PEG linker enhances binding without facilitating inhibitor hydrolysis. Furthermore, the addition of a detection tag to the linker gives a potent and selective activity-based probe which can be applied to the direct detection of $\beta-1,4$-glucanases within a fungal secretome.

\section{Data deposition}

Coordinates and structure factors have been deposited with the PDB, with accession codes 6OYZ (HiCel7B soaked with 1) and 6YP1 (HiCel7B Soaked with 13). Results from the label-free quantitation proteomic experiment have been deposited in the PRIDE database with the accession code PXD019930.

\section{Author contributions}

GJD and HO conceived the study. CB, EP, SPS, JJ, G van der M, and JDCC performed or supervised organic synthesis. BIF performed proteomics. JR, AFJR and GPvanW prepared Aspergillus 
cultures and secretomes. NGSM performed structural biology, intact mass spectrometry, kinetic measurements, and in-gel fluorescence. Manuscript preparation was led by NGSM with help from other authors.

\section{Conflicts of interest}

There are no conflicts to declare.

\section{Acknowledgements}

We thank the Natural Sciences and Engineering Research Council of Canada (Post-Doctoral Fellowship to NGSM), the Royal Society (Ken Murray Research Professorship to GJD), the Biotechnology and Biological Sciences Research Council (BBSRC) (grant BB/R001162/1 to GJD), the Netherlands Organization for Scientific Research (NWO TOP grant 2018-714.018.002 to HSO), the European Research Council (ERC-2011-AdG-290836 "Chembiosphing" to HSO), Diamond Light Source (proposal 18598), and the staff of beamline I03 for assistance with crystal testing and data collection.

\section{Notes and references}

1 L. I. Willems, H. S. Overkleeft and S. I. Van Kasteren, Bioconjugate Chem., 2014, 25, 1181-1191.

2 S. J. Williams, O. Hekmat and S. G. Withers, ChemBioChem, 2006, 7, 116-124.

3 L. M. Chauvigné-Hines, L. N. Anderson, H. M. Weaver, J. N. Brown, P. K. Koech, C. D. Nicora, B. A. Hofstad, R. D. Smith, M. J. Wilkins, S. J. Callister and A. T. Wright, J. Am. Chem. Soc., 2012, 134, 20521-20532.

4 L. Wu, Z. Armstrong, S. P. Schröder, C. de Boer, M. Artola, J. M. Aerts, H. S. Overkleeft and G. J. Davies, Curr. Opin. Chem. Biol., 2019, 53, 25-36.

5 V. Bulone, J. G. Schwerdt and G. B. Fincher, Front. Plant Sci., 2019, 10, 1009.

6 J. M. Fox, P. Jess, R. B. Jambusaria, G. M. Moo, J. Liphardt, D. S. Clark and H. W. Blanch, Nat. Chem. Biol., 2013, 9, 356-361.

7 I. Benoit, H. Culleton, M. Zhou, M. DiFalco, G. AguilarOsorio, E. Battaglia, O. Bouzid, C. P. J. M. Brouwer, H. B. O. El-Bushari, P. M. Coutinho, B. S. Gruben, K. S. Hildén, J. Houbraken, L. A. J. Barboza, A. Levasseur, E. Majoor, M. R. Mäkelä, H. M. Narang, B. Trejo-Aguilar, J. Van Den Brink, P. A. VanKuyk, A. Wiebenga, V. McKie, B. McCleary, A. Tsang, B. Henrissat and R. P. De Vries, Biotechnol. Biofuels, 2015, 8, 1-14.

8 O. Hekmat, Y. W. Kim, S. J. Williams, S. He and S. G. Withers, J. Biol. Chem., 2005, 280, 35126-35135.

9 O. Hekmat, C. Florizone, Y. W. Kim, L. D. Eltis, R. A. J. Warren and S. G. Withers, ChemBioChem, 2007, 8, 2125-2132.

10 S. Atsumi, H. Iinuma, H. Naganawa, H. Nakamura, T. Takeuchi, K. Umezawa and Y. Iitaka, J. Antibiot., 1990, 43, 49-53.
11 T. M. Gloster, R. Madsen and G. J. Davies, Org. Biomol. Chem., 2007, 5, 444-446.

12 J. Jiang, C. L. Kuo, L. Wu, C. Franke, W. W. Kallemeijn, B. I. Florea, E. Van Meel, G. A. van der Marel, J. D. C. Codée, R. G. Boot, G. J. Davies, H. S. Overkleeft and J. M. F. G. Aerts, ACS Cent. Sci., 2016, 2, 351-358.

13 M. D. Witte, W. W. Kallemeijn, J. Aten, K. Y. Li, A. Strijland, W. E. Donker-Koopman, A. M. C. H. Van Den Nieuwendijk, B. Bleijlevens, G. Kramer, B. I. Florea, B. Hooibrink, C. E. M. Hollak, R. Ottenhoff, R. G. Boot, G. A. van der Marel, H. S. Overkleeft and J. M. F. G. Aerts, Nat. Chem. Biol., 2010, 6, 907-913.

14 M. Artola, L. Wu, M. J. Ferraz, C. L. Kuo, L. Raich, I. Z. Breen, W. A. Offen, J. D. C. Codée, G. A. van der Marel, C. Rovira, J. M. F. G. Aerts, G. J. Davies and H. S. Overkleeft, ACS Cent. Sci., 2017, 3, 784-793.

15 L. Wu, J. Jiang, Y. Jin, W. W. Kallemeijn, C. L. Kuo, M. Artola, W. Dai, C. Van Elk, M. Van Eijk, G. A. van der Marel, J. D. C. Codée, B. I. Florea, J. M. F. G. Aerts, H. S. Overkleeft and G. J. Davies, Nat. Chem. Biol., 2017, 13, 867-873.

16 S. P. Schröder, C. De Boer, N. G. S. McGregor, R. J. Rowland, O. Moroz, E. Blagova, J. Reijngoud, M. Arentshorst, D. Osborn, M. D. Morant, E. Abbate, M. A. Stringer, K. B. R. M. Krogh, L. Raich, C. Rovira, J. G. Berrin, G. P. Van Wezel, A. F. J. Ram, B. I. Florea, G. A. van der Marel, J. D. C. Codée, K. S. Wilson, L. Wu, G. J. Davies and H. S. Overkleeft, ACS Cent. Sci., 2019, 5, 1067-1078.

17 L. I. Willems, T. J. M. Beenakker, B. Murray, S. Scheij, W. W. Kallemeijn, R. G. Boot, M. Verhoek, W. E. DonkerKoopman, M. J. Ferraz, E. R. Van Rijssel, B. I. Florea, J. D. C. Codée, G. A. van der Marel, J. M. F. G. Aerts and H. S. Overkleeft, J. Am. Chem. Soc., 2014, 136, 11622-11625. 18 A. R. A. Marques, L. I. Willems, D. Herrera Moro, B. I. Florea, S. Scheij, R. Ottenhoff, C. P. A. A. van Roomen, M. Verhoek, J. K. Nelson, W. W. Kallemeijn, A. Biela-Banas, O. R. Martin, M. B. Cachón-González, N. N. Kim, T. M. Cox, R. G. Boot, H. S. Overkleeft and J. M. F. G. Aerts, ChemBioChem, 2017, 18, 402-412.

19 N. G. S. McGregor, M. Artola, A. Nin-Hill, D. Linzel, M. Haon, J. Reijngoud, A. Ram, M. N. Rosso, G. A. Van Der Marel, J. D. C. Codeé, G. P. Van Wezel, J. G. Berrin, C. Rovira, H. S. Overkleeft and G. J. Davies, J. Am. Chem. Soc., 2020, 142, 4648-4662.

20 G. Davies, S. Tolley, K. Wilson, M. Schülein, H. F. Wöldike and G. Dodson, J. Mol. Biol., 1992, 228, 970-972.

21 L. F. Mackenzie, G. Sulzenbacher, C. Divne, T. A. Jones, H. F. Wöldike, M. Schülein, S. G. Withers and G. J. Davies, Biochem. J., 1998, 335, 409-416.

22 G. Winter, C. M. C. Lobley and S. M. Prince, Acta Crystallogr., Sect. D: Biol. Crystallogr., 2013, 69, 1260-1273.

23 M. D. Winn, C. C. Ballard, K. D. Cowtan, E. J. Dodson, P. Emsley, P. R. Evans, R. M. Keegan, E. B. Krissinel, A. G. W. Leslie, A. McCoy, S. J. McNicholas, G. N. Murshudov, N. S. Pannu, E. A. Potterton, H. R. Powell, R. J. Read, A. Vagin and K. S. Wilson, Acta Crystallogr., Sect. D: Biol. Crystallogr., 2011, 67, 235-242. 
24 A. J. McCoy, R. W. Grosse-Kunstleve, P. D. Adams, M. D. Winn, L. C. Storoni and R. J. Read, J. Appl. Crystallogr., 2007, 40, 658-674.

25 P. Emsley, B. Lohkamp, W. G. Scott and K. Cowtan, Acta Crystallogr., Sect. D: Biol. Crystallogr., 2010, 66, 486-501.

26 G. N. Murshudov, P. Skubák, A. A. Lebedev, N. S. Pannu, R. A. Steiner, R. A. Nicholls, M. D. Winn, F. Long and A. A. Vagin, Acta Crystallogr., Sect. D: Biol. Crystallogr., 2011, 67, 355-367.

27 E. J. Van Rooden, B. I. Florea, H. Deng, M. P. Baggelaar, A. C. M. Van Esbroeck, J. Zhou, H. S. Overkleeft and M. Van Der Stelt, Nat. Protoc., 2018, 13, 752-767.

28 M. V. Aguilar-Pontes, J. Brandl, E. McDonnell, K. Strasser, T. T. M. Nguyen, R. Riley, S. Mondo, A. Salamov, J. L. Nybo, T. C. Vesth, I. V. Grigoriev, M. R. Andersen, A. Tsang and R. P. de Vries, Stud. Mycol., 2018, 91, 61-78.

29 S. P. Schröder, R. Petracca, H. Minnee, M. Artola, J. M. F. G. Aerts, J. D. C. Codée, G. A. van der Marel and H. S. Overkleeft, Eur. J. Org. Chem., 2016, 4787-4794.

30 F. J. Weiberth, H. S. Gill, Y. Jiang, G. E. Lee, P. Lienard, C. Pemberton, M. R. Powers, W. Subotkowski, W. Tomasik, B. J. Vanasse and Y. Yu, Org. Process Res. Dev., 2010, 14, 623-631. 31 D. R. Dabideen and J. Gervay-Hague, Org. Lett., 2004, 6, 973-975. 32 K. Heller, P. Ochtrop, M. F. Albers, F. B. Zauner, A. Itzen and C. Hedberg, Angew. Chem., Int. Ed., 2015, 54, 10327-10330.
33 M. Verdoes, U. Hillaert, B. I. Florea, M. Sae-Heng, M. D. P. Risseeuw, D. V. Filippov, G. A. van der Marel and H. S. Overkleeft, Bioorg. Med. Chem. Lett., 2007, 17, 6169-6171.

34 J. Jiang, T. J. M. Beenakker, W. W. Kallemeijn, G. A. Van Dermarel, H. Van Den Elst, J. D. C. Codée, J. M. F. G. Aerts and H. S. Overkleeft, Chem. - Eur. J., 2015, 21, 10861-10869. 35 M. Schülein, J. Biotechnol., 1997, 57, 71-81.

36 G. Sulzenbacher, M. Schülein and G. J. Davies, Biochemistry, 1997, 36, 5902-5911.

37 V. M. A. Ducros, C. A. Tarling, D. L. Zechel, A. M. Brzozowski, T. P. Frandsen, I. Von Ossowski, M. Schülein, S. G. Withers and G. J. Davies, Chem. Biol., 2003, 10, 619-628.

38 N. N. M. E. Van Peij, J. Brinkmann, M. Vršanská, J. Visser and L. H. De Graaff, Eur. J. Biochem., 1997, 245, 164-173.

39 M. M. C. Gielkens, E. Dekkers, J. Visser and L. H. De Graaff, Appl. Environ. Microbiol., 1999, 65, 4340-4345.

40 N. N. M. E. Van Peij, M. M. C. Gielkens, R. P. De Vries, J. Visser and L. H. De Graaff, Appl. Environ. Microbiol., 1998, 64, 3615-3619.

41 V. Ducros, S. J. Charnock, U. Derewenda, Z. S. Derewenda, Z. Dauteri, C. Dupont, F. Shareck, R. Morosoli, D. Kluepfel and G. J. Davies, J. Biol. Chem., 2000, 275, 23020-23026.

42 L. Lo Leggio, S. Kalogiannis, K. Eckert, S. C. Teixeira, M. K. Bhat, C. Andrei, R. W. Pickersgill and S. Larsen, FEBS Lett., 2001, 509, 303-308. 